\title{
CALIDAD FÍSICA, QUÍMICA Y BACTERIOLÓGICA DEL AGUA ENVASADA EN EL MUNICIPIO DE MONTERÍA
}

\section{PHYSICAL, CHEMICAL AND BACTERIOLOGICAL QUALITY' WATER BOTTLED IN MONTERIA TOWN}

\author{
Mónica M. Simanca ${ }^{1}$, Beatriz E. Álvarez ${ }^{1}$ y Roberth Paternina ${ }^{1}$ \\ Recibido para evaluación: Octubre 5 de 2009 - Aceptado para publicación: Junio 8 de 2010
}

\begin{abstract}
RESUMEN
El agua es vector de peligros físicos, químicos y biológicos importantes para el hombre, por lo que para su consumo es necesario verificar las condiciones de salubridad de la misma, para determinar su aptitud para el consumo humano. El objetivo del presente trabajo fue evaluar los parámetros físicos: $\mathrm{pH}$, color, olor, turbiedad, sólidos totales y conductividad; las características químicas: alcalinidad, sulfatos, dureza total, hierro total, aluminio, cloruros y cloro residual; y las características bacteriológicas: coliformes totales, coliformes fecales y Pseudomonas spp., en 16 empresas envasadoras de agua para consumo humano en el municipio de Montería departamento de Córdoba durante cinco meses. Las variables sólidos totales, $\mathrm{pH}$, alcalinidad, dureza total, conductividad, cloruros, cloro residual y alcalinidad, mostraron diferencias altamente significativas $(p \leq 0,01)$ y los sulfatos diferencias significativas $(p \leq 0,05)$ entre los meses de estudio, indicando que las variaciones de la calidad del agua cruda en el transcurso del estudio influyeron en la calidad final de la misma. Los parámetros de dureza, sólidos totales y conductividad difieren significativamente $(p \leq 0,05)$ entre las empresas envasadoras, como producto de la etapa de floculación para minimizar sólidos y turbiedad en algunas envasadoras. Las variables color, olor, turbiedad, contenido de hierro y aluminio no mostraron diferencias significativas $(p \geq 0,05)$ tanto para las empresas evaluadas como durante los meses de estudio. Los parámetros bacteriológicos, permanecieron constantes durante la investigación. Este estudio evidenció el cumplimiento del Decreto 1575 del 2007 y las Resoluciones 2125 del 2007 y 12186 de 1991 del Ministerio de la Protección Social de Colombia.
\end{abstract}

Palabras clave: potable, características fisicoquímicas, calidad.

\begin{abstract}
Water is a vector of physical, chemical and biological importance to the man, so is necessary to verify the sanitary conditions thereof, to determine their fitness for human consumption. The aim of this study was to evaluate the physical parameters: $\mathrm{pH}$, color, odor, turbidity, total solids and conductivity; the chemical characteristics: alkalinity, sulfate, total hardness, total iron, aluminum, chlorine and residual chlorine, and bacteriological characteristics: total coliforms, fecal coliforms and Pseudomonas spp. Sixteen bottling drinking
\end{abstract}

${ }^{1}$ Universidad de Córdoba. Facultad de Ciencias Agrícolas. Programa de Ingeniería de Alimentos. Km 10 Vía Ciénaga de Oro. Tel/Fax 7561413. Berástegüi-Colombia. msimanca@sinu.unicordoba.edu.co 
water in the city of Montería, department of Córdoba, during five months were evaluated. Total solids, pH, alkalinity, total hardness, conductivity, chlorine and residual chlorine showed highly significant differences $(p \leq 0.01)$ and sulfate significant differences $(p \leq 0.05)$ between the months of study, indicating that variations in the quality of raw water in the course of the study influenced the water final quality. The hardness, total solids and conductivity parameters differ significantly $(p \leq 0.05)$ between the packers, as a result of the flocculation stage to minimize solids and turbidity in some packing. The variables color, odor, turbidity, iron and aluminum content showed no significant differences $(p \geq 0.05)$ for both the evaluated companies and during the months of study. Bacteriological parameters remained constant during the research. This study showed the compliance of Decree 1575 of 2007 and Resolutions 2125 of 2007 and 12186 of 1991 of the Ministry of Social protection of Colombia.

Key Words: drinkable, physical-chemical characteristics, quality.

\section{INTRODUCCIÓN}

El aumento en la demanda de agua potable se debe al aumento de la población, el rápido desarrollo económico y social, la urbanización acelerada, y las mejoras en el nivel de vida y los ecosistemas circundantes (Cheng 2009). Esto ha desencadenado que hoy en día existan numerosas plantas de envasado de agua para el consumo humano destinadas a ser expendidas en todo tipo de establecimientos, desde las ventas ambulantes, tiendas de barrio, supermercados, hasta centros de recreación para adultos. Las enfermedades transmitidas por alimentos (ETA) han sido consideradas como un grave problema de salud pública a escala mundial, donde los alimentos se reconocen como el vector principal de las enfermedades entéricas agudas. En el continente americano las ETA figuran entre las primeras cinco causas de muerte en los menores de 5 años, con una incidencia promedio anual de cuatro episodios diarreicos anuales por niño y con aumentos anuales del número de personas afectadas por ETA, causadas por la ingestión de alimentos mal procesados o pobremente manipulados o preparados (De Curtis et al. 2000). Las enfermedades derivadas por la ingestión de agua, son muy frecuentes en países en desarrollo; es por esto que la vigilancia y control por parte de las entidades gubernamentales sobre las plantas procesadoras de agua es continua y deben ser controladas durante todas las etapas del procesamiento desde la recepción de la materia prima hasta el almacenamiento y distribución del producto empacado; muy a pesar de esto, se evidencia que en el mercado se expenden productos de diferentes calidades y sin registro sanitarios.

El control de la potabilidad y calidad del agua es muy importante, ya que esta es vehículo de transmisión de enfermedades producidas por patógenos intestinales, como bacterias (disentería, cólera, leptospirosis), virus (hepatitis, poliomelitis), protozoos (amebiasis, giardiasis) y helmintos (hidatidosis, bilarsiasis); o por contaminación fisicoquímica debido a la aparición de sustancias no deseables o que siendo elementos de la composición habitual del agua superan la concentración máxima admisible (Arboleda 2000). Para Ilevar a cabo la inspección, vigilancia y control es necesario realizar un seguimiento de las características fisicoquímicas y microbiológicas del proceso 
de potabilización de agua y del producto terminado, con el fin de comparar con los valores normativos (Barrera y Reinstag 2004). Por lo que a través del presente estudio se pretendió caracterizar física, química y bacteriológicamente el agua envasada en el municipio de Montería.

El estudio de la calidad del agua debe incluir el seguimiento de los efectos en la salud, como lesiones, enfermedades, el control delospeligros químicos, físicos y biológicos que pueden causar enfermedades y la vigilancia a través del monitoreo de la exposición de individuos o grupos poblacionales a un agente ambiental (Freitas y Freitas 2005). Una clasificación de los indicadores de la calidad del agua para el consumo humano, utilizada por la Agencia de Protección de Medio Ambiente de los Estados Unidos, distingue entre indicadores primarios y secundarios. Los primarios los componen los productos químicos inorgánicos (metales), los químicos orgánicos (pesticidas), sustancias radioactivas y microorganismos; mientras que los indicadores secundarios, hacen referencia a aspectos estéticos, como el color, turbidez, olor, sustancias en suspensión, entre otros (Beamonte et al. 2004). Desde el punto de vista microbiológico, el examen de la calidad sanitaria del agua tiene por objeto determinar la presencia de ciertos grupos de bacterias, que revelen una contaminación reciente por materia fecal o materia orgánica, siendo el criterio más utilizado la determinación de la clase y número de microorganismos que ésta contiene. Tradicionalmente se han usado ensayos de microorganismos indicadores más que para la determinación de microorganismos patógenos. El grupo de bacterias coliformes ha sido siempre el principal indicador de calidad de los distintos tipos de agua; el número de coliformes en una muestra, se usa como criterio de contaminación y, por lo tanto, de calidad sanitaria de la misma. Esto provee información importante sobre la fuente y el tipo de contaminación presente (Silva et al. 2004).

En ocasiones es conflictivo lograr las condiciones de inocuidad y operación a costo razonable, en las plantas de agua para consumo humano; es claro que la primera condición es imprescindible, por ello las características del agua deben garantizar que no produzca daños, a la red de distribución, ni a las industrias, ni a la economía privada, y que se pueda lograr esto sin tener que realizar algún tratamiento excepcionalmente costoso. Cada país debe establecer su propia normatividad de acuerdo con la calidad de agua cruda que suele obtener, la relación costo-beneficio que puede producir la región, y la presencia de algunos iones (hierro, sulfatos, carbonatos) en el agua que se distribuye (Arboleda 2000). La reglamentación colombiana especifica los criterios y los valores respectivos para evaluar las condiciones físicas, químicas y bacteriológicas de las aguas envasadas destinadas para consumo humano a través del Decreto 1575 del 2007 y las Resoluciones 2125 del 2007 y 12186 de 1991 (Ministerio de Salud de Colombia 1991; Ministerio de la Protección Social de Colombia 2007).

\section{MATERIALES Y MÉTODOS}

El trabajo se realizó en dieciséis (16) envasadoras de agua del municipio de Montería departamento de Córdoba durante cinco (5) meses consecutivos (Agosto a 
Diciembre); se aplicó un muestreo aleatorio, tomando diez (10) bolsas de medio litro (cinco para los análisis y cinco para contramuestra). Para la recolección, conservación y transporte de la muestra se tuvieron en cuenta las recomendaciones citadas en la Resolución 2115 del 2007 y por la APHA et al. (2005). Los análisis se efectuaron dentro de las 36 horas siguientes al muestreo, en un laboratorio perteneciente a la red nacional del Programa Interlaboratorios de Control de Calidad de Agua Potable y Envasada del Instituto Nacional de Salud de Colombia (PICCAP-INS). Para la determinación de la calidad se realizaron los análisis físicos de $\mathrm{pH}$, color, olor, turbiedad, sólidos totales y conductividad; los químicos de alcalinidad, sulfatos, dureza total, hierro, aluminio, cloruros, y cloro residual; y los bacteriológicos coliformes totales, fecales y Pseudomona spp., siguiendo la metodología planteada por la APHA et al. (2005). Los parámetros de validación de los métodos utilizados en este estudio se relacionan en la tabla 1.

El análisis estadístico de los datos se realizó bajo un diseño en bloques completamente al azar, con 16 tratamientos correspondiente a las empresas visitadas; se bloquearon las fluctuaciones de los meses de muestreo. Para el análisis estadístico se utilizó el paquete estadístico R-proyect versión 2.7.1.

Tabla 1. Parámetros de validación de los métodos utilizados

\begin{tabular}{|c|c|c|c|c|c|c|}
\hline PARAMETRO & METODO & $\begin{array}{c}\text { Desviación } \\
\text { Estandar }\end{array}$ & LD & Exactitud & CV & Rango \\
\hline \multicolumn{7}{|c|}{ Análisis Fisicoquímico de Aguas } \\
\hline Turbidez & Turbidimétrico & 0,17 & $0,02 \mathrm{NTU}$ & $0,95-0,99$ & 2,10 & $0,05-100$ \\
\hline Cloro residual & Colorimétrico & 0,28 & $0,01 \mathrm{mg} \mathrm{L}^{-1}$ & $0,93-0,99$ & 3,45 & $0,02-5,00$ \\
\hline $\mathrm{pH}$ & Potenciométrico & 0,22 & 0,3 unidades & $0,96-0.99$ & 1,82 & $1,1-12,8$ \\
\hline Aluminio residual & $\mathrm{KIT}$ & 0,03 & $0,01 \mathrm{mg} \mathrm{L}^{-1}$ & $0,96-1,00$ & 1,11 & $0,01-2,00$ \\
\hline Dureza total & Volumétrico & 2,24 & $2,0 \mathrm{mg} \mathrm{L}^{-1}$ & $0,96-1,05$ & 3,89 & $2,5-300$ \\
\hline Conductividad & Electrométrico & 1,62 & $1 \mathrm{uS} \mathrm{cm}^{-1}$ & $0,95-1,03$ & 1,25 & $0,1-1000$ \\
\hline Sólidos totales disueltos & Electrométrico & 0,85 & $2,0 \mathrm{mg} \mathrm{L}^{-1}$ & $0,97-1,03$ & 1,45 & $5,0-500$ \\
\hline Hierro & Calorimétrico & 0,02 & $0,01 \mathrm{mg} \mathrm{L}^{-1}$ & $0,98-1,01$ & 1,04 & $0,01-5,00$ \\
\hline Color & Comparación visual & 2,44 & 1,0 U Pt-Co & $0,97-1,05$ & 1,05 & $1,00-25,00$ \\
\hline Olor & Organoléptico & NA & NA & & NA & NA \\
\hline Sulfatos & Turbidimétrico & 0,63 & $0,01 \mathrm{mg} \mathrm{L}^{-1}$ & $0,96-1,07$ & 1,44 & $0,01-50,00$ \\
\hline Cloruros & Volumétrico & 0,74 & $1,0 \mathrm{mg} \mathrm{L}^{-1}$ & $0,93-0.98$ & 3,11 & $2,5-300$ \\
\hline Alcalinidad total & Volumétrico & 2,21 & $2,0 \mathrm{mg} \mathrm{L}^{-1}$ & $0,98-1,10$ & 3,56 & $2,5-300$ \\
\hline \multicolumn{7}{|c|}{ Análisis Bacteriológico de Aguas } \\
\hline Coliformes totales & FPM / NMP & NA & NA & & NA & NA \\
\hline Coliformes fecales & FPM / NMP & $\mathrm{NA}$ & $\mathrm{NA}$ & & NA & NA \\
\hline Pseudomona spp. & FPM / NMP & NA & NA & & NA & NA \\
\hline
\end{tabular}




\section{RESULTADOS Y DISCUSIÓN}

El análisis estadístico de las variables físicas y químicas mostrado en la tabla 2 revela que existieron diferencias altamente significativas $(p \leq 0,01)$ durante los meses del estudio en las variables $\mathrm{pH}$, sólidos totales, alcalinidad, dureza total, conductividad, cloruros, cloro residual y diferencias significativas $(p \leq 0,05)$ en la variable sulfato, lo cual se puede explicar por la incidencia de la composición del agua cruda, materia prima tomada del Río Sinú, como consecuencia de los fenómenos de precipitación durante los meses de muestreo, los que inciden en "lavado de los suelos" los cuales por el arrastre de sustancias aportan sólidos y sustancias disueltas a la fuente que abastece los sistemas de potabilización de la ciudad (IDEAM 2009).

En cuanto a las empresas solo existieron diferencias significativas $(p \leq 0,05)$ en la variable dureza, sólidos totales y conductividad, lo que puede atribuirse tanto a la composición del agua cruda como a las diferencias en los procesos de potabilización de la misma. Por otra parte, las variables color, olor, turbiedad, contenido de aluminio, hierro, no mostraron diferencias significativas tanto para las empresas evaluadas como para los meses de estudio (agosto a diciembre).

Los valores de $\mathrm{pH}$ oscilaron entre 6,2 y 7,69 (Figura 1a), encontrándose ligeramente inferiores a los aceptados por la norma colombiana. Difieren con los valores de 8,3 a 8,6 encontrados en la ciudad de Sincelejo reportados porVidal et al. (2009) pero coinciden con los encontrados por Hurtado y Gardea (2005) quienes reportaron valores de $\mathrm{pH}$ entre
5,8 y 7,8 en agua envasada para consumo en la ciudad de Jalisco, México. Por otra parte, difieren de estudios realizados por Madrazo e Iriarte (2005) en territorio venezolano donde están alrededor de 4,0 a 6,0; pero aclaran que durante los mismos meses del estudio, los suelos de la población son ácidos y ricos en azufre. Otros estudios reportan también $\mathrm{pH}$ ácido en aguas minerales para consumo alrededor de 5,89 (Muñoz et al. 2004).

El parámetro de Turbiedad osciló entre los valores de 0,0 y 1,4 UNT con una media general de 0,153 UNT, el cual concuerda con los valores entre 0,3 y 1 UNT en el estudio de aguas envasadas en Montería (Barrera y Reinstag 2004) y en México (Muñoz et al. 2004). Los valores de color estuvieron alrededor de 7,5 UPC y los valores de olor se reportaron en su totalidad como aceptable; mientras que Barrera y Reinstag (2004) en su estudio reportaron la variable color entre 0,6 y 4 UPC y la variable olor normal. El valor promedio de los sólidos totales durante los meses de estudio fue $66,43 \mathrm{mg} \mathrm{L}^{-1}$, oscilando entre 58 y $78 \mathrm{mg} \mathrm{L}^{-1}$ (Figura 1b). Estudios realizados en diferentes localidades reflejan valores similares (Moreno et al. 2004). En España se reportan valores de sólidos totales inferiores de $250 \mathrm{mg} \mathrm{L}^{-1}$ (Moratilla y Yélamos 2000). La variable conductividad presentó valores de 131 US $\mathrm{cm}^{-1}$ en promedio, y se relaciona con los sólidos totales disueltos en el agua y la turbiedad (Figura 2a).

El análisis de alcalinidad de las muestras evaluadas demuestra que el agua envasada en Montería durante los meses evaluados estaba dentro de los valores exigidos por la ley colombiana. Los valores se encontraban entre 
Tabla 2. Análisis estadísticos de variables físicas y químicas

\begin{tabular}{|c|c|c|c|c|c|}
\hline pH & Df & Sum Sq & Mean Sq & F value & $\operatorname{Pr}(>F)$ \\
\hline Bloque & 4 & 4,6368 & 1,1592 & 19,8360 & $1,902 \mathrm{e}-10^{* * *}$ \\
\hline Empresa & 15 & 1,1301 & 0,0753 & 1,2892 & 0,2374 \\
\hline Residuals & 60 & 3,5064 & 0,0584 & & \\
\hline \multicolumn{6}{|l|}{ DUREZA } \\
\hline Bloque & 4 & 1262,95 & 315,74 & 8,6699 & $1,366 \mathrm{e}-05 * * *$ \\
\hline Empresa & 15 & 1020,39 & 68,03 & 1,8679 & $0,04543 *$ \\
\hline Residuals & 60 & 2185,05 & 36,42 & & \\
\hline \multicolumn{6}{|c|}{ TURBIEDAD } \\
\hline Bloque & 4 & 0,3469 & 0,0867 & 1,2230 & 0,3106 \\
\hline Empresa & 15 & 1,2556 & 0,0837 & 1,1805 & 0,3114 \\
\hline Residuals & 60 & 4,2544 & 0,0709 & & \\
\hline \multicolumn{6}{|c|}{ SÓLIDOS TOTALES } \\
\hline Bloque & 4 & 354,13 & 88,53 & 4,0197 & $0,005921^{* *}$ \\
\hline Empresa & 15 & 640,09 & 42,67 & 1,9375 & $0,036700 *$ \\
\hline Residuals & 60 & 1321,47 & 22,02 & & \\
\hline \multicolumn{6}{|c|}{ CONDUCTIVIDAD } \\
\hline Bloque & 4 & 1086,5 & 271,6 & 3,6918 & $0,009412 * *$ \\
\hline Empresa & 15 & 2367,4 & 157,8 & 2,1452 & $0,019228 *$ \\
\hline Residuals & 60 & 4414,3 & 73,6 & & \\
\hline \multicolumn{6}{|c|}{ ALCALINIDAD } \\
\hline Bloque & 4 & 2951,64 & 737,91 & 15,1421 & $1,299 \mathrm{e}-08 * * *$ \\
\hline Empresa & 15 & 640,11 & 42,67 & 0,8757 & 0,5933 \\
\hline Residuals & 60 & 2923,94 & 48,73 & & \\
\hline \multicolumn{6}{|c|}{ CLORUROS } \\
\hline Bloque & 4 & 378,96 & 94,74 & 12,0903 & $2,86 \mathrm{e}-07^{* * *}$ \\
\hline Empresa & 15 & 136,44 & 9,10 & 1,1608 & 0,3265 \\
\hline Residuals & 60 & 470,17 & 7,84 & & \\
\hline \multicolumn{6}{|c|}{ CLORO RESIDUAL } \\
\hline Bloque & 4 & 0,29196 & 0,07299 & 12,9083 & $1,211 \mathrm{e}-07 * * *$ \\
\hline Empresa & 15 & 0,07283 & 0,00486 & 0,8587 & 0,6112 \\
\hline Residuals & 60 & 0,33927 & 0,00565 & & \\
\hline \multicolumn{6}{|c|}{ SULFATOS } \\
\hline Bloque & 4 & 92,07 & 23,02 & 3,0732 & $0,02276 *$ \\
\hline Empresa & 15 & 104,58 & 6,97 & 0,9309 & 0,53607 \\
\hline Residuals & 60 & 449,38 & 7,49 & & \\
\hline
\end{tabular}


15,6 y $66,6 \mathrm{mg} \mathrm{L}^{-1} \mathrm{CaCO}_{3}$ con valor promedio de 28,94 $\mathrm{mg} \mathrm{L}^{-1} \mathrm{CaCO}_{3}$ (Figura 2b), los cuales se encuentran por debajo de $150 \mathrm{mg} \mathrm{L}^{-1} \mathrm{CaCO}_{3}$ para denominar al agua como cálcica (Espejo 2001). El contenido de sulfatos de las aguas estudiadas presentó diferencias significativas a bajos porcentajes de significancia ( $\leq \leq 0,05)$, con un promedio de $22,48 \mathrm{mg} \mathrm{L}^{-1} \mathrm{SO}_{4^{\prime}}$ lo cual está dentro de la norma colombiana. Se designa un agua como sulfatada cuando los valores se encuentran por encima de $200 \mathrm{mg} \mathrm{L}^{-1} \mathrm{SO}_{4}$

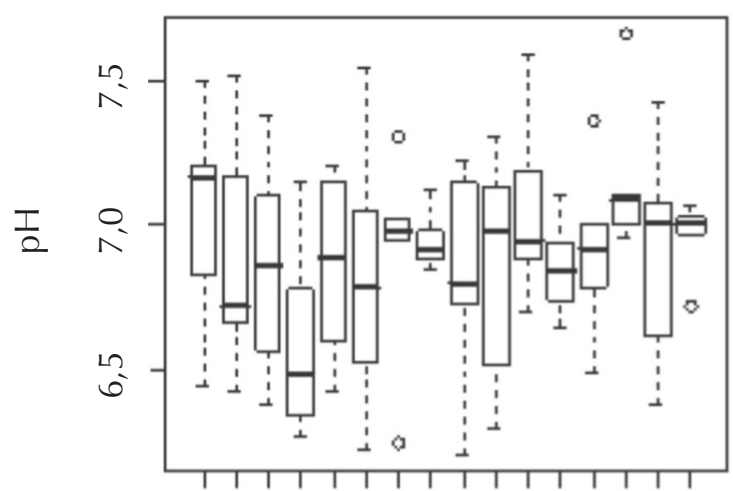

A $\quad C \quad E \quad G \quad I \quad K \quad M \quad O$

EMPRESAS

a) $\mathrm{pH}$

Figura 1. Valores de $\mathrm{pH}$ y Sólidos Totales

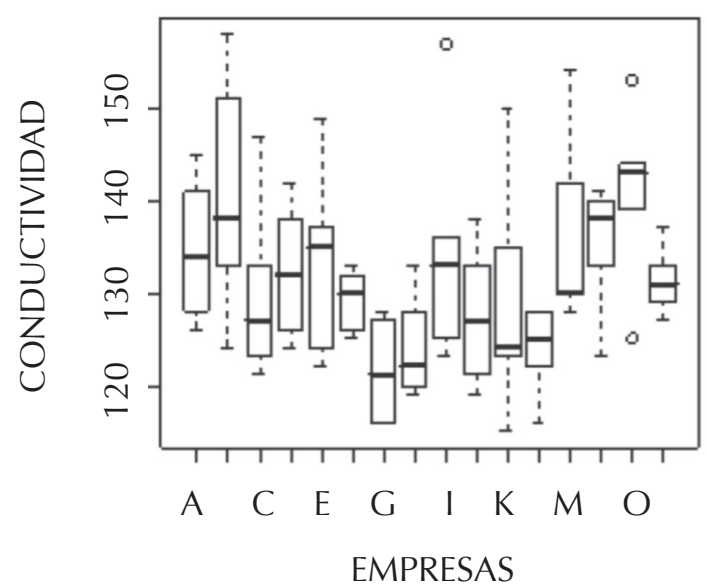

a) Conductividad

Figura 2. Valores de Conductividad y Alcalinidad
(Espejo 2001). Las diferencias entre muestras se deben al uso de sulfato de aluminio para flocular la turbiedad que pueda tener el agua de abastecimiento. Los valores de dureza se encuentran entre 24 y $74 \mathrm{mg} \mathrm{L}^{-1} \mathrm{CaCO}_{3}$ con un promedio de 51,71 mg L-1 $\mathrm{CaCO}_{3}$ (Figura 3a), cumpliendo con las especificaciones establecidas. Este parámetro relaciona el contenido de sales de Ca y Mg, y en el caso de aguas manantiales el valor reportado es mayor aún, debido al fenómeno de coprecipitación

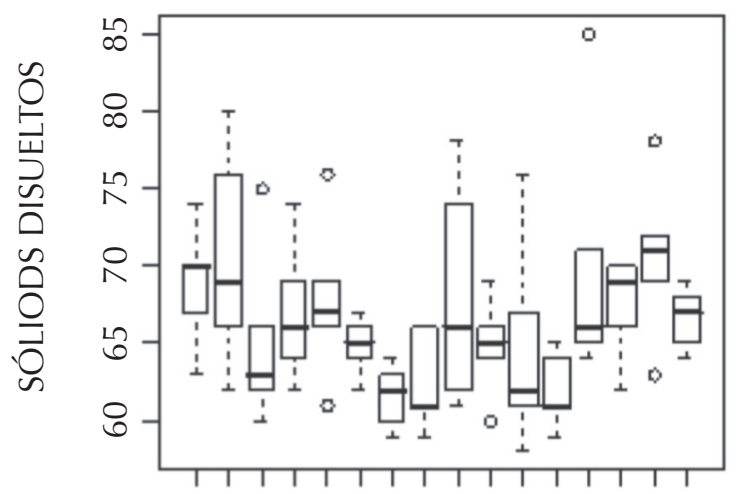

A $C$ C

EMPRESAS

b) Sólidos Totales

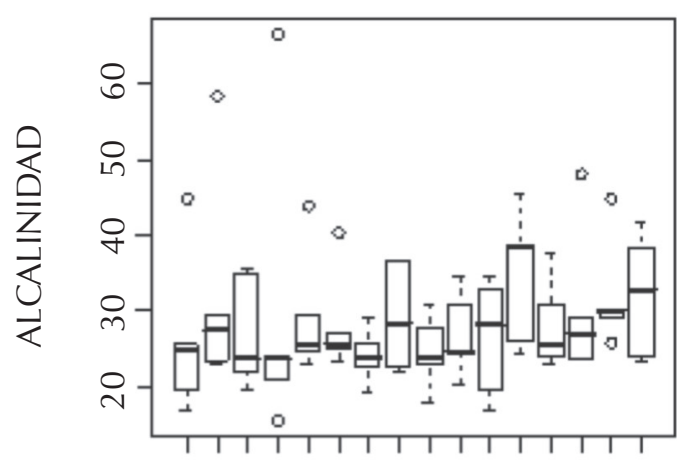

A C E G I K

EMPRESAS

b) Alcalinidad 
de iones pesados como plomo, zinc, entre otros y a la disminución de sustancias trazas presentes (Muñoz et al. 2004). En España se reportan valores de $\mathrm{Ca}^{++}$entre 0 y $337 \mathrm{mg} \mathrm{L}^{-1}$ y de $\mathrm{Mg}$ entre 0,3 y $315 \mathrm{mg} \mathrm{L}^{-1}$ (Martínez et al. 2008). Estudios sugieren evitar la reducción de los valores de dureza porque los tratamientos pertinentes pueden aumentar la agresividad del agua en las tuberías y aumenta el riesgo de corrosión del plomo (Berdonces 2008).

Los parámetros de hierro y aluminio se mantuvieron constantes y menor a 0,01 mg $\mathrm{L}^{-1}$ Fe y 0,07 $\mathrm{mg} \mathrm{L}^{-1} \mathrm{Al}$, respectivamente. Los valores de hierro bivalente superiores a 1 mg $\mathrm{L}^{-1}$ en agua para consumo ameritan la denominación de agua ferruginosa o que contiene hierro (Espejo 2001); por otra parte se puede decir que el contenido de estos oligoelementos en el agua, es importante, por su papel de integrarse a grandes complejos por acción directa o indirecta con los microorganismos y de intervenir catalíticamente como microcomponente (Muñoz et al. 2004). Estos cambios en los parámetros físicos se pueden relacionar con las fluctuaciones de las condiciones del agua del acueducto la cual es la materia prima para las empresas envasadoras, por la recepción de efluentes generados por la propia actividad humana, urbana, agrícola e industrial, que constituye la contaminación artificial del agua del río; igualmente por la disolución y arrastre de sustancias naturales que son propias de los terrenos, por los que previamente han circulado las aguas, que podríamos definir como contaminación natural (Beamonte et al. 2004).

Los valores de cloruros reportados durante los meses de investigación están entre 8,7 y 23,8 mg L ${ }^{-1} \mathrm{Cl}^{-}$, los cuales están dentro de la norma y próximos a los reportados por Barrera y Reinstag (2004) entre 4 y $10 \mathrm{mg} \mathrm{L}^{-1} \mathrm{Cl}^{-}$; y por debajo de los $200 \mathrm{mg} \mathrm{L}^{-1} \mathrm{Cl}^{-}$para denominarla como clorurada (Espejo 2001) y de $500 \mathrm{mg} \mathrm{L}^{-1} \mathrm{Cl}^{-}$ reportados por la literatura como generadores de sabor salino (Muñoz et al. 2004). Para ciertas poblaciones se recomienda la supervisión de la mineralización del agua de consumo, tal es el caso de los pacientes hipertensos, los cuales después de ciertas semanas consumiendo aguas de alta mineralización (24 $\left.\mathrm{mg} \mathrm{L}^{-1} \mathrm{Cl}^{-}\right)$ se ha comprobado una disminución en la excreción de calcio y potasio (Frailde et al. 2006). En el caso de los lactantes se debe tener control estricto del contenido de sodio, flúor, calcio y cloruros para evitar la sobrecarga salina para los riñones, por lo que debe restringirse el contenido mineral del agua con que se preparan las fórmulas de inicio, de modo que sea inferior al de la leche de vaca y semejante al de la leche humana madura. Miñana (2004) recomienda que el parámetro de los cloruros debe estar alrededor de $78 \mathrm{mg} \mathrm{L}^{-1} \mathrm{Cl}^{-}$por día. El análisis de cloro residual presento un promedio $0,102 \mathrm{mg} \mathrm{L}^{-1} \mathrm{Cl}_{2}$ con valores hasta $0,3 \mathrm{mg} \mathrm{L}^{-1}$ $\mathrm{Cl}_{2}$ (Figura $3 \mathrm{~b}$ ), el cual es consistente con el parámetro de la norma. Para la desinfección del agua de consumo se reportan valores de $0.5 \mathrm{mg} \mathrm{L}^{-1} \mathrm{Cl}_{2}$ (Luján 2001). Se ha encontrado actividad antimicrobiana en el agua a partir de una concentración de $14 \mathrm{mg} \mathrm{L}^{-1}$ de cloro residual y $\mathrm{pH}$ de 2,7 , con reducciones de 4 ciclos logarítmicos en bacterias mesófilas aerobias, así como también reduce coliformes y hongos y levaduras (Chavez et al. 2004).

En el presente estudio se observó un comportamiento constante respecto a los 


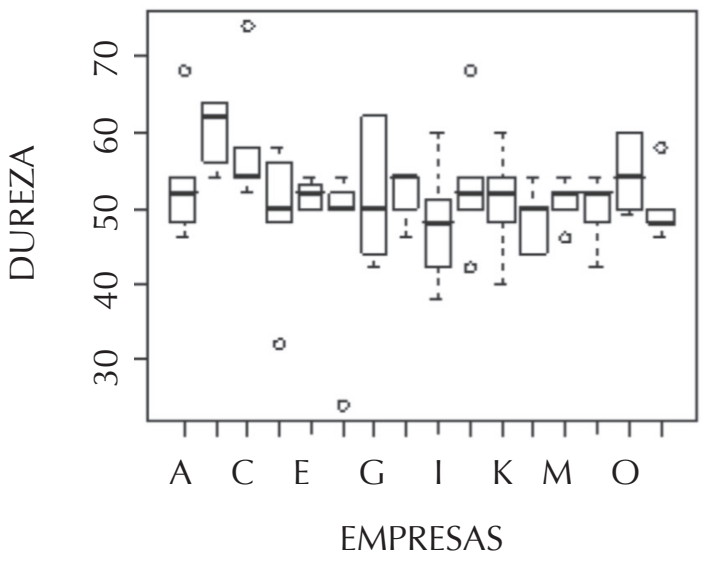

a) Dureza

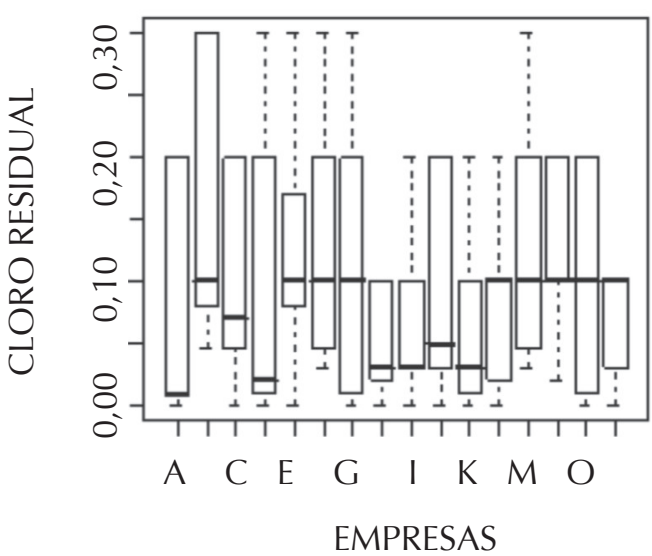

a) Cloro Residual

Figura 3. Valores de Dureza y Cloro Residual

parámetros bacteriológicos, reportándose ausencia tanto de coliformes totales y fecales como de Pseudomona spp., los cuales cumplen las disposiciones de la normatividad y son consistentes con los reportados por Barrera y Reinstag (2004); evidenciando que los tratamientos para la desinfección del agua son eficientes en la remoción de la carga bacteriológica del agua envasada en Montería.

Entre los parámetros más investigados figuran la presencia de coliformes, en especial E. coli; además se conoce al agua como vector de microorganismos como Helicobacter pylori (Gião et al. 2008). Estudios en agua de río y agua envasada muestran presencia de E. coli (Bouteleux et al. 2005; Liu et al. 2008) y la relación de este microorganismo con otros patógenos (Lehtola et al. 2007). Además, se ha demostrado una relación entre la presencia de biopelículas de E. coli con la cantidad de fósforo y hierro adicionados en el tratamiento del agua envasada (Appenzeller et al. 2005; Juhna et al. 2007). Estudios microbiológicos de agua para consumo humano han relacionado la estación del año con la presencia de microorganismos patógenos. En zonas como Wisconsin-Estados Unidos, se han registrado reovirus, enterovirus y adenovirus en ciertas épocas; se registran enfermedades diarreicas por Cryptosporidium sp. y otros patógenos en época de primavera (Sedmak et al. 2005). Se ha evidenciado también la presencia de otros patógenos en el agua envasada como Mycobacterium sp, igualmente, hongos patógenos, parásitos y virus (Szabo et al. 2007 y Helmi et al. 2008) y así como el impacto de los métodos de desinfección sobre los mismo (Wu et al. 2005).

\section{CONCLUSIONES}

- Los parámetros fisicoquímicos y microbiológicos del agua envasada comercializada en el municipio de Montería durante el tiempo de estudio evidencian un agua de buena calidad, cumpliendo con todos los requisitos de la normativa nacional.

- Las variables pH, sólidos totales, alcalinidad, dureza total, conductividad, cloruros, cloro residual y alcalinidad, mostraron diferencias 
entre los meses de estudio, indicando que las variaciones de la calidad del agua cruda en el transcurso del estudio influyeron en la calidad final de la misma.

- Este estudio mostró que la calidad del agua cruda influye directamente en la calidad final del agua envasada, evidenciándose por las fluctuaciones presentadas en las variables $\mathrm{pH}$, sólidos totales, alcalinidad, dureza total, conductividad, cloruros, cloro residual y alcalinidad.

- Los parámetros bacteriológicos, permanecieron constantes durante la investigación.

\section{REFERENCIAS}

American Public Health Association, American Water Works Association, Water Enviroment Federetion. 2005.

Standard Methods for the examination of water and wasterwater. APHA, AWWA and WEF, Washington D.C., $p$ 2-7, 4-138.

Appenzeller, B., Yanez, C., Jorand, F., y Block, J. 2005. Advantage provided by iron for Escherichia coli growth and cultivability in drinking water. Applied and Environmental Microbiology Journal 71(9): 5621-5623.

Arboleda, J. 2000. Teoría y práctica de la purificación del agua. Editorial Mc Graw Hill, Bogotá, p31.

Barrera, C. y Resinstag P. 2004. Estudio de la calidad físico-química, microbiológica y organoléptica del agua tratada y envasada en las plantas de tratamiento del municipio de Montería. Tesis Ingeniero de Alimentos, Universidad de Córdoba, Montería.

\section{Beamonte, E., Bermúdez J., Casino, A. y Veres}

E. 2004. Un indicador global para la calidad del agua, aplicación a las aguas superficiales de la Comunidad Valenciana. Revista Estadística Española 46(156): 357-384.

Berdonces, J. 2008. La problemática del tratamiento del agua potable. Revista Medicina Naturista 2(2): 69-75.

Bouteleux, C., Saby, S., Tozza, D., Cavard, J., Lahoussine, V., Hartemann, P. y Mathieu, L. 2005. Escherichia coli behavior in the presence of organic matter released by algae exposed to water treatment chemicals. Applied and Environmental Microbiology Journal 71(2): 734-740.

Chavez, G., Medina I., De Colmenarez, B., Mercado, M. y Carrascal, A. 2004. Producción de agua electrolizada para eliminación de microorganismos en lechuga. Revista de la Facultad de Ciencias Pontificia Universidad Javeriana 9(1): 91-100.

Cheng, H., Hu, Y. y Zhao, J. 2009. Meeting China's Water Shortage Crisis: Current Practices and Challenges. Environmental Science and Technology Journal 43(2): 240-244. 
De Curtis, M., Franceschi, O., y De Castro, N. 2000. "Determinación de la calidad microbiológica de alimentos servidos en comedores de empresas privadas." Archivos Latinoamericanos de Nutrición 50(2):177-182.

Espejo, C. 2001. Las aguas de consumo envasadas en España. Trasvases muy rentables y nada cuestionados. Revista Papeles de Geografía 34(1):125-142.

Fraílde, R., Silva, C., de Enciso, M., Rodriguez, C., Freire, A., Rodriguez, J. y Tejeiro, J. 2006. Efecto del consumo de agua bicarbonatada sódica con diferentes de minerales en pacientes hipertensos. Revista Medicina Naturista 9: 450459.

Freitas, M. y Freitas C. 2005. A vigilância da qualidade da água para consumo humano desafios e perspectivas para o Sistema Único de Saúde. Ciência \& Saúde Coletiva 10(4): 993-1004.

Gião M., Azevedo, N., Wilks, S., Vieira, M. y Keevil, C. 2008. Persistence of Helicobacter pylori in Heterotrophic Drinking-Water Biofilms. Applied and Environmental Microbiology Journal 74(19): 5898-5904.

Helmi, K., Skraber, S., Gantzer, C., Willame, R., Hoffmann, L. y Cauchie, H. 2008. Interactions of Cryptosporidium parvum, Giardia lamblia, Vaccinal Poliovirus Type 1, and Bacteriophages \{phi\} X174 and MS2 with a drinking water biofilm and a wastewater biofilm. Applied and Environmental Microbiology 74(7): 2079 -2088.

Hurtado, R. y Gardea, J. 2005. Estimación de la exposición a fluoruros en Los Altos de Jalisco, México. Revista Salud Pública de México 47(1):58-63.

Instituto de Hidrología, Metrología, y Estudios Ambientales (IDEAM). 2009. Boletín Informativo sobre el monitoreo del Fenómeno del Niño. Número 1, p 2.

Juhna, T., Birzniece, D. y Rubulis, J. 2007. Effect of phosphorus on survival of Escherichia coli in drinking water biofilms. Applied and Environmental Microbiology Journal 73(11): 37553758.

Lehtola, M., Torvinen, E., Kusnetsov, J., Pitkanen, T., Maunula, L., Von Bonsdorff, C., Martikainen, P., Wilks, S., Keevil, C. y Mienttinen, I. 2007. Survival of Mycobacterium avium, Legionella pneumophila, Escherichia coli, and caliciviruses in drinking water-associated biofilms grown under high-shear turbulent flow. Applied and Environmental Microbiology Journal 73(9): 2854 -2859 .

Liu, Y., Gilchrist, A., Zhang, J. y Li, X. 2008. Detection of viable but nonculturable Escherichia coli O157: H7 bacteria in drinking water and river water." Applied and Environmental Microbiology 74(5): 1502 -1507. 
Luján, J. 2001. Un hidrogel de hidóxido de aluminio para eliminar el arsénico del agua. Revista Panamericana de Salud Pública, 9(5): 302-305.

Madrazo, J. e Iriarte, M. 2005. Condición del agua para beber y preparar alimentos de la población Warao de la Barra de Makareo, municipio Tucupita, estado Delta Amacuro, Venezuela. Revista del Instituto Nacional de Higiene Rafael Rangel 36(1): 13-20.

Martínez, A., Peris, P., Reyes, R. y Guañabens, N. 2008. Aporte de calcio, magnesio y sodio a través del agua embotellada y de las aguas de consumo público: implicaciones para la salud. Revista Medicina Clínica 131(17): 641-646.

Ministerio de la Protección Social de Colombia. 2007. Decreto 1575: Sistema para la protección y control de la calidad del agua para consumo humano potable. Ministerio de la Protección Social de Colombia, Bogotá, p 3-4.

Ministerio de la Protección Social de Colombia, Ministerio de Ambiente, Vivienda y Desarrollo Territorial. 2007. Resolución 2115: Características, instrumentes básicos y frecuencias del sistema de control y vigilancia para la calidad del agua para consumo humano. Bogotá, p 2-7.

Ministerio de Salud de Colombia. 1991. Resolución 12186: Condiciones para los procesos de obtención, envasado y comercialización de agua potable tratada con destino al consumo humano. Ministerio de Salud de Colombia, Bogotá, p 1-4.

Miñana, V. 2004. Agua de bebida en el lactante. Anales de Pediatría 60(2): 161-9.

Moratilla, P. y Yélamos, J.G. 2000. Hidrogeoquímica de las aguas minerales de la península Ibérica. Revista Geogaceta 28(1):101-104.

Moreno, M., Morales, A., Chaparro, A. y Garzon, J. 2004. Evaluación y dinámica de uso del recurso hídrico en el corregimiento de Barú (Cartagena, Bolivar, Colombia). Acta Biológica Colombiana 9(1): 23-36.

Muñoz, N., Araujo, P. y Falqué, E. 2004. Potencialidad terapéutica del agua del manantial de SANDIM. Ciencia y Tecnología Alimentaria 4(3): 177 184

Sedmak,G., Bina, D., MacDonald, J. y Couillard, L. 2005. Nine-year study of the occurrence of culturable viruses in source water for two drinking water treatment plants and the influent and effluent of a wastewater treatment plant in milwaukee, wisconsin (August 1994 through July 2003). Applied and Environmental Microbiology Journal 71(2): 1042-1050.

Silva, J., Ramírez, L., Alfieri, A., Rivas, G. y Sanchez, M. 2004. Determinación de microorganismos indicadores de calidad sanitaria coliformes 
totales, coliformes fecales $y$ aerobios mesófilos en agua potable envasada y distribuida en San Diego, estado Carabobo, Venezuela. Revista Sociedad Venezolana de Microbiología 24(1-2): 46-49.

Szabo, J., Rice, E. y Bishop, P. 2007. Persistence and decontamination of Bacillus atrophaeus subsp. globigii spores on corroded iron in a model drinking water system. Applied and Environmental Microbiology Journal 73(8): 2451-2457.
Vidal, J., Consuegra, A., Gomescáseres, L. y Marrugo, J. 2009. Evaluación de la calidad microbiológica del agua envasada en bolsas producida en Sincelejo-Colombia. Revista MVZ Córdoba 14(2):1736-1744.

Wu, Y., Clevenger, T. y Deng, B. 2005. Impacts of goethite particles on UV disinfection of drinking water. Applied and Environmental Microbiology Journal 71(7): 4140-4143. 